\title{
A Case Report of Folie'a Deux: Husband-and-Wife
}

Ryan M. Nishihara

John A. Burns School of Medicine, Honolulu, Hawaii

Craig T. Nakamura

John A. Burns School of Medicine, Honolulu, Hawaii

Follow this and additional works at: https://jdc.jefferson.edu/jeffjpsychiatry

Part of the Psychiatry Commons

Let us know how access to this document benefits you

\section{Recommended Citation}

Nishihara, Ryan M. and Nakamura, Craig T. (1993) "A Case Report of Folie'a Deux: Husband-and-Wife," Jefferson Journal of Psychiatry. Vol. 11 : Iss. 1 , Article 9.

DOI: https://doi.org/10.29046/JJP.011.1.012

Available at: https://jdc.jefferson.edu/jeffjpsychiatry/vol11/iss $1 / 9$

This Article is brought to you for free and open access by the Jefferson Digital Commons. The Jefferson Digital Commons is a service of Thomas Jefferson University's Center for Teaching and Learning (CTL). The Commons is a showcase for Jefferson books and journals, peer-reviewed scholarly publications, unique historical collections from the University archives, and teaching tools. The Jefferson Digital Commons allows researchers and interested readers anywhere in the world to learn about and keep up to date with Jefferson scholarship. This article has been accepted for inclusion in Jefferson Journal of Psychiatry by an authorized administrator of the Jefferson Digital Commons. For more information, please contact: JeffersonDigitalCommons@jefferson.edu. 


\title{
A Case Report of Folie 'a Deux: Husband-and-Wife
}

\author{
Ryan M. Nishihara \\ Craig T. Nakamura
}

\begin{abstract}
Shared paranoid disorder is a relatively rare psychiatric disorder in which paranoid delusions are transferred from one individual to one or more other susceptible person(s) in close association. Folie a deux describes a shared paranoid disorder involving two people and is characterized by a complex dependant relationship between the involved individuals. Provided there is no additional underlying psychopathology, there is a good prognosis for the submissive partner. Here we present a case report and discussion of folie a deux involving a husband and wife. Although folie a deux is a relatively uncommon disorder, it is important to recognize such cases due to the potential for recovery in the submissive partner.
\end{abstract}

The term folie a deux, also known as psychosis of association or shared paranoid disorder, describes a syndrome in which paranoid delusions are transferred from one individual to one or more other susceptible person(s). Dewhurst and Todd set forth three diagnostic criteria for folie a deux (1):

1. There must be a marked similarity between the delusional content of the partners' psychosis,

2. The partners must accept, support and share each other's delusional ideas, and

3. There must be positive evidence that the partners have been intimately associated over a long period of time.

Similarly, the DSM III R (2) diagnostic criteria for folie a deux are:

1. A delusion(s) develops (in a secondary case), in the context of a close relationship with another person, or persons, with an already established delusion(s) (the primary case).

2. The delusion(s) of the secondary case are similar in content to the delusion(s) of the primary case.

3. Immediately prior to the onset of the induced delusion the secondary case did not have a psychotic disorder.

Cases of induced psychosis have been reported dating back to 1563 in which Weir described the "cure of nuns afflicted en masse by demoniacal possession." However, 
there was no established name for this disorder until Lasegue and Falret coined the phrase "Folie a deux" in 1877 (4). They initially described folie a deux as a social rather than psychiatric phenomenon. The inducer created the delusions from his/her psychosis and imposed them upon a "passive" individual (induced); the induced subject was not truly psychotic, but instead "absurdly credulous" (4).

There are four types of folie a deux: 1) Folie impose'e; 2) Folie simultane'e; 3) Folie communique'e; and 4) Folie induite. Lasegue and Falret described folie impose'e, the most common form of folie a deux, in which the primary case is typically dominant, intelligent, forceful, and autonomous. The secondary case is usually dependant, submissive, highly suggestible, less intelligent, more passive, infantile, and more prone to hysteria $(5,6)$. He/she offers little resistance to accepting the ideas of the primary subject and does not elaborate upon those ideas. Several authors have characterized the passive person with a premorbid personality as "prepsychotic," and with "a marked personality disturbance with suspicious, histrionic, antisocial, or dependent traits" (6). Social isolation of the subjects is common in this form of folie a deux and has been found to limit environmental input and opportunities for reality testing. However, one reassuring feature of folie impose'e is that psychotic symptoms usually recede upon separation of the involved subjects.

The second form of folie a deux is folie simultane'e, named by Regis. It describes the simultaneous appearance of identical psychoses in two predisposed persons who have had a long and intimate association with one another. There is often a genetic link between the subjects and appears with greater prevalence among the elderly (7). Enoch stated that there is usually no dominant partner in folie simultane'e and that separation does not appear to alleviate the symptomatology (5).

Folie communique'e, coined by Marandon de Montyel, involves the transfer of psychotic delusions after a long period of resistance by the secondary or passive partner. The recipient of the delusions subsequently develops his/her own delusions, independent of the primary subject's, which typically persist following separation (5).

The fourth type of folie a deux coined by Lehmann, is folie induite or induced psychosis, which may be considered a variant of folie communique'e. In this form, new delusions are added to old ones under the influence of another deluded patient. The secondary person enriches the newly acquired delusions. In folie induite, in contrast to folie communique'e, the secondary subject actually creates his/her own delusions and therefore, separation is not an effective mode of therapy (5).

It is important to realize that the various forms of folie a deux represent a spectrum and that there are various methods of classifying the disorder. Another method of classifying folie a deux is to name the variation according to the number of individuals involved. Examples are, folie a trois (three), folie a quarte (four), folie a cinque (five), and folie a familie (the family). The most common forms of folie a deux typically occur between genetically related individuals, however, non-sanguinous types do occur on occasion. We present one such example, a case between husbandand-wife. 


\section{CASE REPORT}

Mrs. A is a 23 year-old Hispanic female who came to our attention when she was admitted to the forensic unit of a state psychiatric hospital. After one month of hospitalization, she was discharged from the psychiatric hospital and transferred to a state correctional facility. She was transferred back to the initial psychiatric hospital 6 months later.

Mrs. A admitted experiencing auditory hallucinations when she was very young; hearing "strange" noises and foot steps in her home. At the age of 14 years, she frequented the beach with her family and conversed with a "male voice" which told her that she would meet a man who was "fair skinned, tall, big-eared, compassionate, caring, and loving," and he would end her loneliness. During periods when she was unable to speak with the ocean, she would speak to the stars and the moon. Her parents harassed her for talking to the moon and called her "crazy."

Mrs. A denied any physical or sexual abuse as a child, but claimed that she did not have a happy childhood and was emotionally neglected by her parents. She felt that she was not a part of her family and isolated herself from them. She later isolated herself from others, frequently spending time alone during her adolescent years, truant from school, reading romantic novels, and abusing alcohol.

There were no known psychiatric illnesses in Mrs. A's family. However, she does recall her maternal grandmother being called a "witch" by neighbors because she was able to "speak with spirits." Mrs. A's family practiced Espiritismo, a religion in which spirits are able to contact the living through "predisposed" mediums. Mrs. A said that she is a believer of the religion, but is not as avid as her other family members.

Mr. A is a 27 year-old Hispanic male who was diagnosed with paranoid schizophrenia at the age of 8 . The primary disturbances in his thought content include delusions of being controlled, delusions of reference, and persecutory delusions; his disturbances in perception consist primarily of command, visual, and auditory hallucinations. The patient's thought content consists of 3 primary "good demons" named Romanoff, The Baron, and La Belle and 19 secondary "evil and good demons." As a child Mr. A did not have many friends and was the focus of ridicule by his peers. Mr. A was an only child and stated that his family was dysfunctional with a domineering and physically abusive father and a passive mother. He remembered informing his father of the children at school taunting him. His father's reaction was to place a gun in $\mathrm{Mr}$. A's hand and urged him to "shoot them."

Mr. A took out a personal ad in a single's magazine seeking a companion. Mrs. A replied and the couple was married within a week. On their wedding night, Mrs. A first saw Mr. A become "possessed" by the demon Romanoff. Mr. A/Romanoff stated that he was the god of the ocean with whom she conversed throughout her childhood. Initially, she was startled and afraid, but as the night progressed, her fear was replaced with relief as she became re-acquainted with her "childhood companion."

The couple continued to isolate themselves from society. Over the next few 
years, the frequency of Mr. A's "possessions" increased and Mrs. A became familiar with the other demons in his delusions and integrated them into her world. She never had personal contact with these demons, but was informed of their existence by $\mathrm{Mr}$. A/Romanoff. She continued to have auditory hallucinations, but now experienced tactile and visual hallucinations as well.

The principle demon in the couple's psychosis was Romanoff who was described as a "fallen angel with greyish-black wings and possessed a sword with gems upon it." La Belle was described as a "tall beautiful lady dressed in silver with long silver hair and who carries a chalice full of blood from [Mrs. A's] enemies." Since the introduction of The Baron to Mrs. A, through Romanoff/Mr. A, The Baron has existed solely in Mrs. A's dreams. He does not speak to her, but only points to animate objects. She described The Baron as a tall gentleman dressed in black who carried a sword. Despite Romanoff and The Baron's common goal of protecting the couple, they are constantly in conflict with one another.

The couple moved from state to state attempting to find Mr. A a steady job. Romanoff predicted the destinations the couple would travel to and the outcomes of each relocation. Throughout their travels, Mr. and Mrs. A experienced financial and social difficulties. Romanoff also predicted that Mrs. A would be raped and that Mr. A was to die in their latest place of relocation. Despite this prediction, the couple again relocated and invested in a handgun.

The auditory hallucinations and delusions continued to plague the couple. One night, while dining at a restaurant, Mr. A saw two strangers $\mathrm{Mr}$. B and Mr. C laughing between themselves and perceived their laughter as being directed towards him. After arguing, Mr. and Mrs. A returned to their apartment to avoid further escalation of the situation. While at the apartment, Mr. A once again "became" Romanoff. He informed Mrs. A that "The enemies were laughing at us. You must kill them or they will kill you." Mr. and Mrs. A then returned to the restaurant where Mr. A shot and killed both Mr. B and Mr. C. The couple fled to their apartment where Romanoff now informed them to kill themselves. A dual suicide was then attempted. Mrs. A swallowed vaginal suppositories, perfume, and "allergy pills." The mode of suicide for Mr. A was not remembered by the patient. The police then traced the couple to their apartment room where they were discovered, arrested, and admitted to a psychiatric hospital.

\section{HOSPITAL COURSE}

Mr. A was admitted to a maximum security forensic unit, while Mrs. A was admitted to a high security forensic unit in the state psychiatric hospital. The results of Mrs. A's physical exam were unremarkable. Her admission laboratory studies were within normal limits with the exception of a gram negative UTI and a microcytic anemia.

During the initial interview Mrs. A was asked what she would do if she was acquitted of her charges. Her response at that time was "I don't know. 'Mr. A' is my life and if I can't have him, I have no life." During her hospitalization, Mrs. A 
continued to have visual, auditory, and tactile hallucinations as well as suicidal ideations. Her treatment plan consisted primarily of separation from her husband. The patient remained agitated and psychotic and thus was started on pharmacotherapy consisting of Haldol and Xanax. Mrs. A refused to partake in any of the ward activities and spent most of her time either reading or sleeping. However, she continued to hear the voice of Romanoff and had multiple suicide attempts consisting of self strangulation with a telephone cord and pillow case, repeatedly dropping a metal bed frame onto her head, and wrist slashings with a butter knife. Suicide precautions were taken and Mrs. A was placed on one-to-one observation, however, once the observation periods were over, the suicide attempts resumed.

Initially Mrs. A was given telephone privileges with her husband and stated that the demons were more active both during and after speaking to him. She begged to see her husband and stated "If I don't see him, the bad demons will bother me. Romanoff is more powerful when 'Mr. A' is near." When the couple was given visitation privileges, the staff noted that the couple's psychoses increased in severity. It was then decided that both telephone and visitation privileges between $\mathrm{Mr}$. and Mrs. A were to stop, with the hope of alleviating the patients' symptoms.

Romanoff later told Mrs. A to escape from the hospital and to kill herself if she failed, for "she would never be able to be with her husband again." Mrs. A occasionally went into a trance-like state, during which she claimed to be possessed by the demon Romanoff with intentions of destroying the hospital if not released. These incidents stopped after terminating contact between Mr. and Mrs. A.

Mrs. A was later switched to Thorazine and Cogentin with continued separation from her husband. The continued separation and neuroleptic regimen resulted in marked relief of her symptoms. Currently, Mrs. A takes Thorazine (100 mg PO qd) and Cogentin (2 mg PO qd) and is no longer plagued by "Romanoff" or "The Baron." However, she continues to have auditory hallucinations. She no longer wishes to see her husband and is in the midst of a divorce. Mrs. A currently remains in the high security forensic unit in the state psychiatric hospital and is more active in group activities, has gained self-confidence, feels more independent, assertive, and has a positive outlook regarding her life. Mr. A remains in the maximum security forensic unit in the state hospital and was found incompetent to stand trial due to his unresponsiveness to psycho- and pharmacotherapy.

\section{DISCUSSION}

Enoch stated that folie a deux is undoubtedly an intriguing condition and is perhaps the most impressive example of a pathological relationship to be found (8). A key factor in the development of this disorder is a close association between the two partners. One would imagine that folie a deux would be a relatively common disorder; with the development of mental health centers and a reduction of psychiatric hospitals, the number of chronic paranoid psychotics in the community has increased. With the majority of these individuals living in foster homes, group homes, and on the streets, the social interaction of these individuals has also increased (9). 
Nevertheless, shared paranoid psychoses continue to be quite rare. While there is no data on the incidence or prevalence of folie a deux, in his 1974 review, Lucian Floru covered at least 245 cases from the psychiatric literature in English, French and German (10). Nearly $90 \%$ of all reported cases occur within a family (majority being blood relatives); the most common relationship found between blood relatives is between 2 sisters and the most common relationship between non-sanguinous relatives is between husband-and-wife (5). Gralnick reported that among 109 pairs recorded in the literature, 40 consisted of two sisters, 26 of husband and wife, 24 of mother and child, 11 of two brothers, 6 of brother and sister, and 2 of father and child $(11,12)$.

The couple presented here fulfill the diagnostic criteria presented by Dewhurst and Todd and DSM III $\mathrm{R}$ regarding folie a deux $(1,2)$. However, it is difficult to differentiate the subgroup of folie a deux that this couple fulfills. The possibility of a concomitant diagnosis of folie induite, folie simultane'e, and/or folie impose'e may be possible. It is questionable whether Mrs. A did have a psychotic illness during her adolescent years, in which case the diagnosis of folie induite would be made. Also, both Mr. and Mrs. A may have been predisposed to a psychosis, resulting in a shared psychosis. However, the diagnosis of folie simultane'e usually involves partners who have had a long association with each other prior to the development of the common delusional beliefs, which Mr. and Mrs. A did not have. Although the possibility of an induced psychosis between a psychotic individual and a highly suggestible individual (folie impose'e) may exist, it is difficult to exclude the possibility that Mrs. A was initially psychotic. Thus, although the subgroup of folie a deux cannot be determined for this couple, it is obvious from the presented information that the couple did fulfill the criteria of folie a deux.

Much of the literature differentiates diagnostically between the primary partner (inducer) and the secondary partner (induced). The factors implicated in obtaining dominance by the primary partner are superiority in age, intelligence, force, and imagination $(1,6)$. The characteristics of the secondary partner's premorbid personality have been described by many authors as being overdependent, insecure, suggestible, less intelligent, seclusive, and depressed; they were also noted to have a lower self-esteem $(1,5,6,13,14)$. In nearly all of the reported cases, the dominant partner is diagnosed as either schizophrenic or paraphrenic (6) with the submissive partner having a schizophrenic/paraphrenic disorder, or having a personality disorder, dementia, or mental retardation. As in this case, it is sometimes difficult to determine which partner is the inducer and which partner is the induced. We believe that the distinction between the induced and inducer is more difficult with the diagnosis of folie communique'e or folie induite than folie impose'e.

Both Mr. and Mrs. A led isolated lives during their childhood and adolescence. Their isolation from society continued throughout their adulthood and marriage. As Dewhurst and Todd stated, "they tend to isolate themselves not only from the community at large but even from their own neighbors. The seclusiveness of these individuals originated, no doubt, from a distrustful attitude to mankind: a distrust that eventually tends to degenerate into a paranoid psychosis" (1). The social isolation thus would allow the more domineering partner to influence the weaker 
partner. The isolation has also been found to disable the weaker/vulnerable partner from society's influences and puts him/her under the influence of the domineering individual. Other reported factors contributing toward the development of folie a deux include poverty, language difficulties, physical disabilities, impaired sexuality, disorganized role patterns, and personality instability. The social isolation of Mrs. A along with her impressionability may have influenced the development of her shared paranoid psychosis (1).

In this case, personality instability is a major factor in the development of folie a deux. Mrs. A was diagnosed as having a dependent personality disorder which may have contributed to her susceptibility in acquiring folie a deux. Because Mrs. A fulfilled the DMS III R diagnostic criteria for a dependent personality disorder she would rely more on her husband's decisions and opinions, making herself more susceptible to her husband's psychosis. Sacks stated that an alternative dynamic approach to the development of the syndrome is attributed to the intense attachment of the two partners. In this situation the induced seeks to preserve the relationship with the inducer by adopting his or her delusions because he/she feels that the threat of the loss is greater than the fear of psychosis (6). Once separated, the induced is no longer exposed to the inducer's disturbed thought content. Nearly 6 months after being hospitalized, Mrs. A realized that she had been betrayed by her husband, despite initially feeling "sorry for him." She also realized that the primary reason she believed the stories Mr. A told her was because she had loved him, despite the beatings and humiliation that he imposed on her.

As with Mr. and Mrs. A, much of the thought content in patients with folie a deux consists of persecutory delusions. Both Mr. and Mrs. A believed that the primary reason $\mathrm{Mr}$. A was not able to obtain a steady job was related to his employers feeling jealous of him. They also believed that harm was to happen to them and thus were very suspicious of other people. Although persecutory delusions are the primary thought content in folie a deux, other types of delusions such as religious, body image, infestations, and grandiose are by no means rare (1,6,7). Although the religious content of this couple's delusions is apparent, we are uncertain of its significance.

Prognostic and therapeutic factors in folie a deux are complicated by the fact that many patients with the disorder present for treatment individually. It is also a relatively rare disorder with no systematic treatment regimen that has been found to be effective. In fact, the treatment modalities presented in previous case reports are as diverse as the presenting symptoms of those patients. The essential therapeutic step in the treatment of folie a deux is separation of the inducer and the induced. With this separation, the induced usually reverts to their baseline cognitive function, however, this has not been universally the case. Enoch found that separation of the two partners resulted in only a $40 \%$ recovery rate for the secondary partner who had a personality disorder, with a much lower recovery rate if the secondary partner had a prior schizophrenic diagnosis (5). Other therapeutic modalities for either the primary or the secondary partners include pharmacotherapy, ECT, increasing personal autonomy and/or increasing social interactions. 


\section{CONCLUSION}

Mrs. A has been found competent to stand trial and awaits her court hearing concerning the shooting incident of Mr. B and Mr. C. Mr. A has been found unfit to stand trial and was sent back to the maximum security forensic unit at the state psychiatric hospital for further treatment and observation.

As illustrated in Mrs. A's case, recovery with separation and pharmacotherapy does occur. Due to this fact, it is important to consider this disorder in the differential diagnosis of psychosis. Enoch stated that when considering the prognosis and treatment it is important to keep in mind those underlying clinical and social factors which are potent in the production of an environment conducive to the sharing of delusions, i.e. separation (5).

The possibility exists that the religious beliefs of Espiritismo may have played a role in both Mr. and Mrs. A's trance-like state; however Mrs. A stated that she does not practice the religion. It is the authors' opinion that further investigation regarding religious influences and the couple's psychosis be investigated. It is also recommended that further studies concerning the subject of cross cultural psychiatry and the relationship of religious influences and folie a deux be considered (15).

\section{BIBLIOGRAPHY}

1. Dewhurst K, Todd J: The Psychosis of Association-Folie A Deux. J Nerv Ment Dis 1956; 124:451-459

2. American Psychiatric Association: Diagnostic and Statistical Manual of Mental Disorders, 3rd ed (revised). Washington, DC, American Psychiatric Association, 1987

3. Weir J: De praestigiis daemonum. (Paris) 1563. Histoires, disputes et discours des illusions et imposstures des diables, etc. (Reprint of 1579 trans.), 1885

4. Lasegue C, Falret J: La folie a deux ou folie communique'e. Ann Med Psychol (Paris) 1877; 18:321-355

5. Enoch MD, Trethowan WH: Uncommon Psychiatric Syndromes, 2nd ed. Littleton, Mass, John Wright-PSG, 1979

6. Sacks MH: Folie a Deux. Compr Psychiatry 1988; 29:270-277

7. Munro A: Folie a Deux Revisited. Can J Psychiatry 1986; 31:233-234

8. Lazarus A: Folie a Deux: psychosis by association or genetic determinism?. Compr Psychiatry 1985; 26:129-135

9. Bankier RG: Role Reversal in folie a deux. Can J Psychiatry 1988; 33:231-232

10. Floru L: Der Iuierte Wahn: Theoretischer Uberlick and Benerkungen am ramde von 12 fallen. Fortschr Neurologie Psychiatrie Grenzgebite 1974; 42:76-96

11. Gralnick A: Folie a deux. The psychosis of association. Psychiatric Quart 1942; 16:230-263

12. Salama AA, Wilson R: Two Sisters folie a Deux: A Case of Attempted Suicide. Can J Psychiatry 1982; 27:334-335

13. Pande NR, Gulabani DM: Folie a Deux: A Socio-psychiatric Study. British Journal of Psychiatry 1990; 156:440-442

14. Scharfetter C: Studies of heredity in symbintic psychoses. Int J Ment Health 1972; $1: 116-123$

15. Alonso L, Jeffrey WD: Mental Illness Complicated by the Santeria Belief in Spirit Possession. Hosp Community Psychiatry 1988; 39:1188-1191 